\title{
Viper Venom Components Affecting Angiogenesis
}

\author{
T.F. Huang C.H. Yeh W.B. Wu \\ Pharmacological Institute, College of Medicine, National Taiwan University, \\ Taipei, Taiwan, ROC
}

\section{Key Words}

Angiogenesis · Endothelial cell · Cytokine . Integrin - Disintegrin - Glycoprotein lb . Metalloproteinase

\begin{abstract}
Angiogenesis is a complex process consisting of the proliferation, migration and differentiation of endothelial cells, and it is essential for the progression of malignant solid tumors. In this report, we examine the effects of disintegrins (e.g. rhodostomin and accutin) and glycoprotein-lb-binding proteins (e.g. agkistin) on each step in angiogenesis using in vitro and in vivo models. Rhodostomin (but not agkistin) inhibited the viability of human umbilical vein endothelial cells (HUVECs) and capillary tube formation of HUVECs. Rhodostomin also inhibited HUVEC migration and invasion evoked by basic fibroblast growth factor (bFGF). In in vivo studies, rhodostomin inhibited bFGF-, but not vascular-endothelial-growth-factor (VEGF)-
\end{abstract}

\begin{tabular}{ll}
\hline KARGER & ( ) 2002 S. Karger AG, Basel \\
Fax +4161306 1234-0147/01/0316-0192\$17.50/0 \\
$\begin{array}{l}\text { E-Mail karger@karger.ch } \\
\text { www.karger.com }\end{array}$ & $\begin{array}{l}\text { Accessible online at: } \\
\text { www.karger.com/journals/hae }\end{array}$
\end{tabular}

associated angiogenesis in chick chorioallantoic membrane model, blocked both bFGF and B16F10 melanoma cell-induced neovascularization, and suppressed the growth of subcutaneously inoculated B16F10 solid tumor, leading to a prolonged survival of the C57BL/6 mice treated with rhodostomin. The antiangiogenic effects of rhodostomin on bFGF-treated HUVECs may be mainly related to the blockade of the interaction of endothelial $\alpha_{v} \beta_{3}$ and extracellular matrix.

Copyright $\odot 2002$ S. Karger AG, Basel

\section{Introduction}

Angiogenesis, which consists of a complex process of the development of new capillaries from preexisting vessels, plays a critical role in a variety of normal physiological events, such as female menstrual cycle, bone remodeling and wound healing. In contrast, many pathological conditions are also characterized by undesirable neovascularization, including

Dr. T.F. Huang, Pharmacological Institute, College of Medicine National Taiwan University

No. 1, Jen-Ai Road, Sec. 1, Taipei (Taiwan, ROC)

Tel. +886223123456 ext. 8332, Fax +886223417930

E-Mail turfu@ccms.ntu.edu.tw 
diabetic retinopathy, tumor growth, metastasis and various inflammation diseases [1]. Tumor angiogenesis involves several processes, including endothelial proliferation, migration, invasion and tube formation that are regulated by cell adhesion receptors and specific angiogenic growth factors produced by tumor cells and the surrounding stroma [2, 3]. Integrins are a family of heterodimeric transmembrane receptors that mediate cell-cell and cell-extracellular matrix (ECM) interaction [4]. The function of integrins during angiogenesis has been studied extensively with $\alpha_{v} \beta_{3}$, which is one of several Arg-Gly-Asp (RGD)-dependent integrins [5]. In vivo, expression of this integrin is strongly upregulated in angiogenic endothelial cells, where it plays a critical role in angiogenesis induced by basic fibroblast growth factor (bFGF), tumor necrosis factor- $\alpha$ (TNF- $\alpha$ ) or fragments of human tumors in corneal or chick chorioallantoic membrane (CAM) model [6]. Friedlander et al. [7] demonstrated that angiogenesis depends on cytokines and that vascular cell integrin $\alpha_{v} \beta_{3}$ is required when angiogenesis was stimulated by bFGF or TNF- $\alpha$, whereas angiogenesis, induced by vascular endothelial growth factor (VEGF), transforming growth factor- $\beta$ or phorbol ester, depends on $\alpha_{\mathrm{v}} \beta_{5}$.

Glycoprotein (GP) Ib is an adhesive receptor expressed both on platelets and endothelial cells. Binding of plasma von Willebrand factor (vWF) to platelet GPIb plays a critical role in the earliest phase of primary hemostasis, which consists of the anchoring of platelets to injured vessel walls [8]. In contrast to platelets, the functions of endothelial GPIb for vWF is not well established. Several studies have demonstrated the presence of GPIb complex expressed on the endothelial cell surface and the upregulation of endothelial GPIb by cytokines, i.e., TNF and interferon [9-12]. It has been shown that endothelial GPIb participates in HUVEC binding to sickle cell erythrocyte [13] and also promotes platelet bridging to endothelial cells [14]. Recently, Lian et al. [15] assumed that endothelial GPIb may contribute to mediate the process of endothelial cell migration during wound repair in vivo.

Snake venoms contain many unique components that affect cell-matrix interaction. Disintegrins represent a family of low molecular weight, cysteine-rich polypeptides that bind specifically to integrins $\alpha_{\mathrm{IIb}} \beta_{3}, \alpha_{5} \beta_{1}$ and $\alpha_{v} \beta_{3}$ expressed on platelets and other cells, including vascular endothelial cells and some tumor cells, leading to inhibition of platelet aggregation, inhibition of cell adhesion, migration and angiogenesis [16]. On the other hand, some GPIb-binding venom proteins modulate vWF-GPIb interaction, leading to platelet activation, inhibition of platelet aggregation [17] or mediating HUVEC adhesion [18]. Agkistin (also named agkicetin [19]), belonging to C-type lectin polypeptides derived from the viper venom of Agkistrodon acutus, specifically inhibited human platelet aggregation and agglutination triggered by ristocetin in the presence of vWF in vitro by acting as platelet GPIb antagonist. Furthermore, agkistin is a potent antithrombotic agent because it pronouncedly blocked platelet plug formation in an experimental model in vivo [20].

In this study, we will describe the effects of disintegrin (e.g. rhodostomin, accutin) and GPIb antagonists (e.g. agkistin) on each distinct step of angiogenesis, including proliferation, migration, invasion and differentiation in HUVECs in vitro and in the chick CAM model in vivo. On the other hand, the antitumor activity of disintegrin was also evaluated by examining its effect on B16F10 melanoma tumor-induced angiogenesis and on tumor mass, and the survival rate in tumor-bearing C57BL/6 mice. 
Fig. 1. Effect of rhodostomin on bFGF-induced HUVEC proliferation and on B16F10 melanoma cell viability. a-c HUVECs $\left(4 \times 10^{4} /\right.$ $\mathrm{ml}$ ) were seeded on 24-well plates. After attachment, cells were treated with the indicated concentration of test compounds for $48 \mathrm{~h}$ in the presence or absence (naive) of bFGF (30 ng/ml). Cell proliferation was measured by cell number counting (a), metabolic activity using WST-1 reagent (b), and BrdU incorporation (c). For control, HUVECs were grown in M199 containing $2 \%$ FBS or $20 \%$ FBS for $48 \mathrm{~h}$ and then assayed for cell proliferation. d The inhibition of B16F10 melanoma cell viability was analyzed in the absence (control) or presence of various concentrations of rhodostomin. After the incubation for 24,48 or $72 \mathrm{~h}$, cells were stained with MTT and lysed. The absorbance was read by an ELISA reader. Data are presented as means $\pm \operatorname{SEM}(\mathrm{n}=3){ }^{*} \mathrm{p}<0.01$ vs. bFGF-primed cells in the absence of rhodostomin $(\mathbf{a}-\mathbf{c})$.

\section{Materials and Methods}

Rhodostomin and agkistin were purified from the snake venom of Agkistrodon rhodostoma and A. acutus. HUVECs were isolated from human umbilical cord veins and identified by positive immunofluorescence staining of human vWF antigen. The B16F10 murine melanoma cells were maintained in DMEM containing 10\% FBS. Some in vitro studies were used in this work, including proliferation and viability as-
Naive cells

bFGF-primed cells
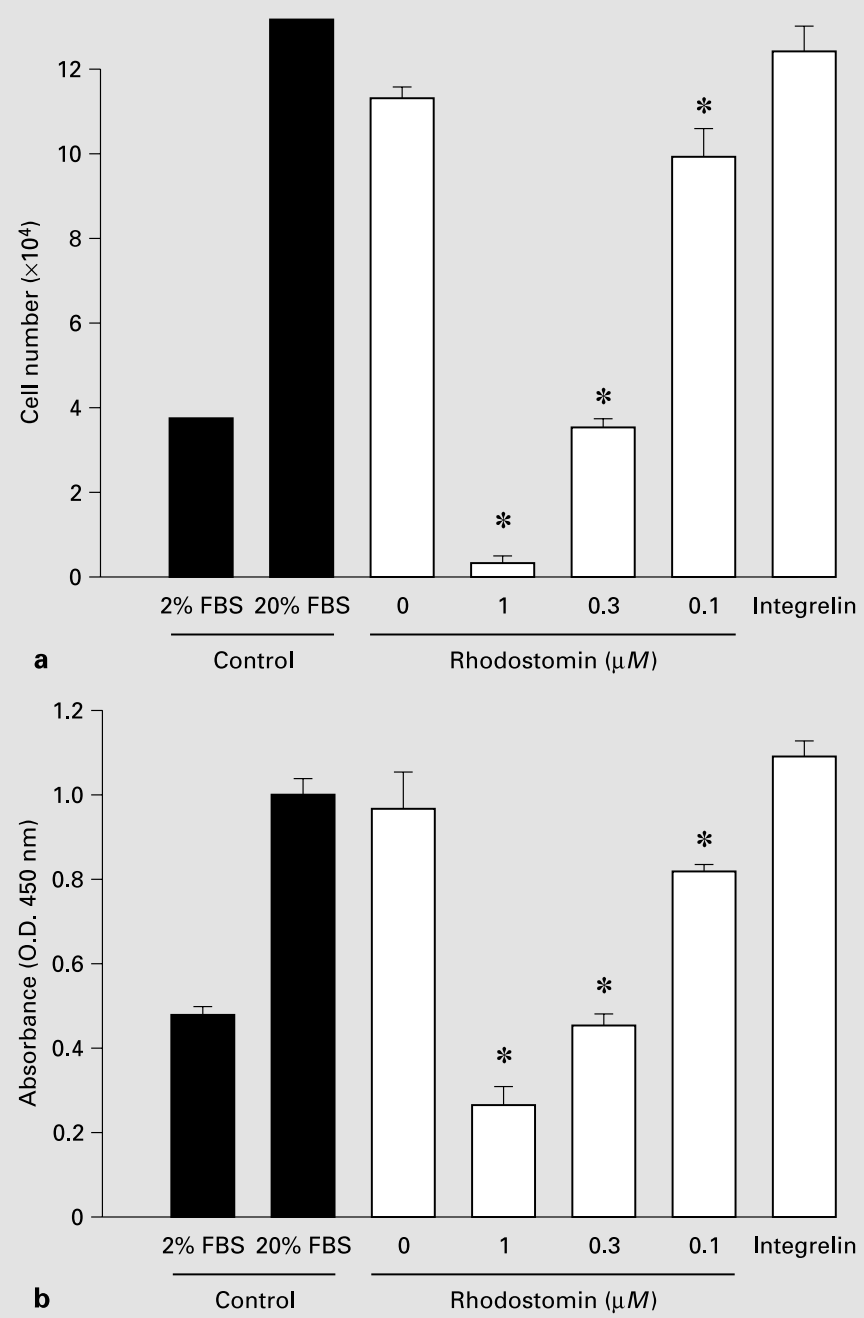

b

Control

Rhodostomin $(\mu M)$ says, migration (chemotaxis and haptotaxis) and invasion assays using a Transwell apparatus, and Matrigel tube formation assays. For in vivo studies, the chick CAM and Matrigel plug angiogenesis assays were performed. Flow cytometry studies were used for the determination of endothelial integrins and GPIb expression in either naive or cytokine-primed HUVECs. Finally, the effect of rhodostomin on B16F10 tumor model in C57BL/6 mice were performed to examine the antitumor activity of disintegrin. 


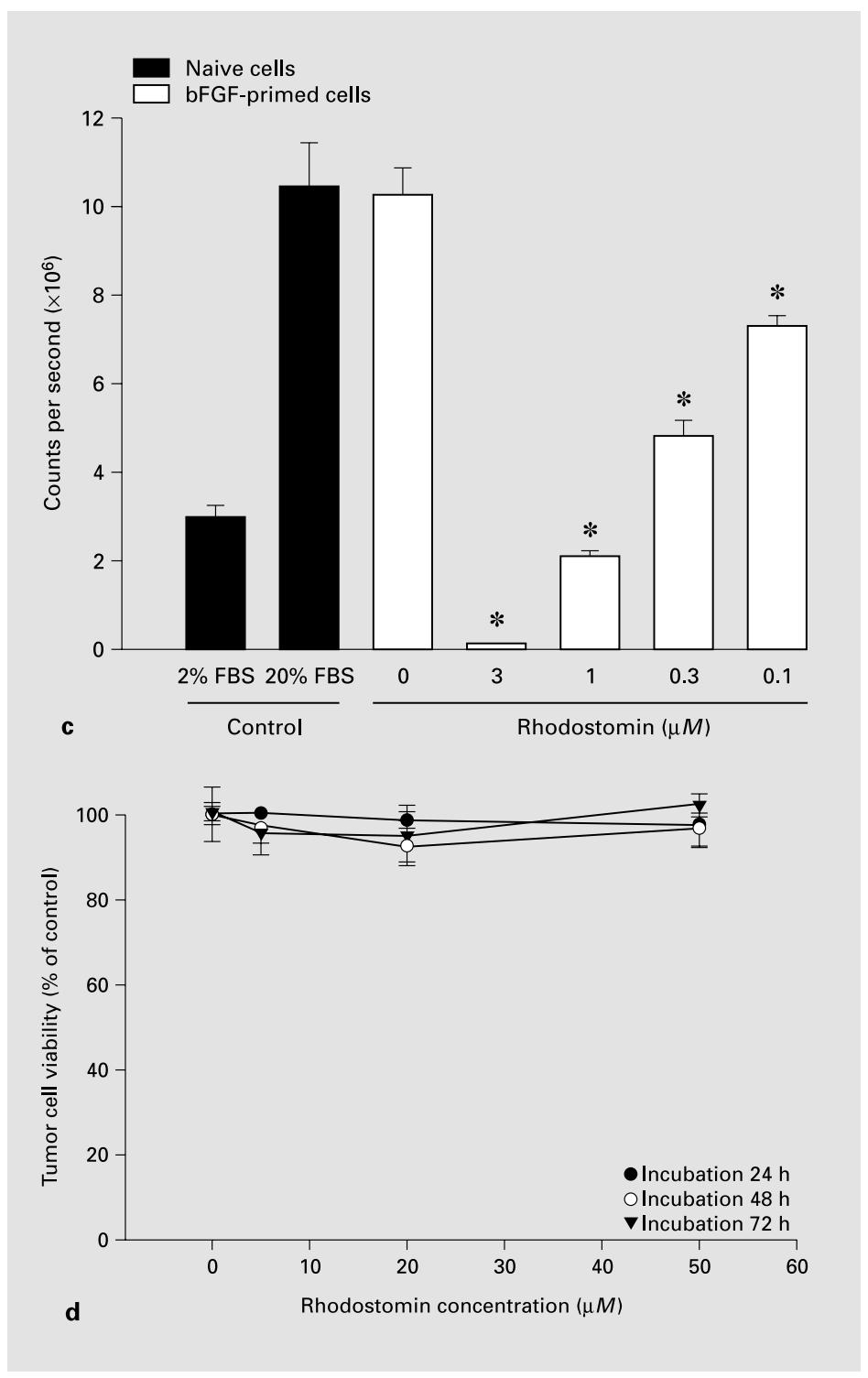

\section{Results}

Effects of Disintegrin and GPIb Antagonist on HUVEC Proliferation

The assays for cell proliferation were performed by counting cells with a hemocytometer and by determining the cell metabolic activity with tetrazolium salt (i.e., WST-1).
Furthermore, DNA synthesis was measured by BrdU incorporation and used as a proliferation marker. As shown in figure 1, endothelial cells incubated with bFGF $(30 \mathrm{ng} / \mathrm{ml})$ in $2 \%$ FBS for $48 \mathrm{~h}$, as well as those grown in medium-containing 20\% FBS, showed a 2.5to 3.5 -fold increase in three proliferation assays compared with control cells (grown in 


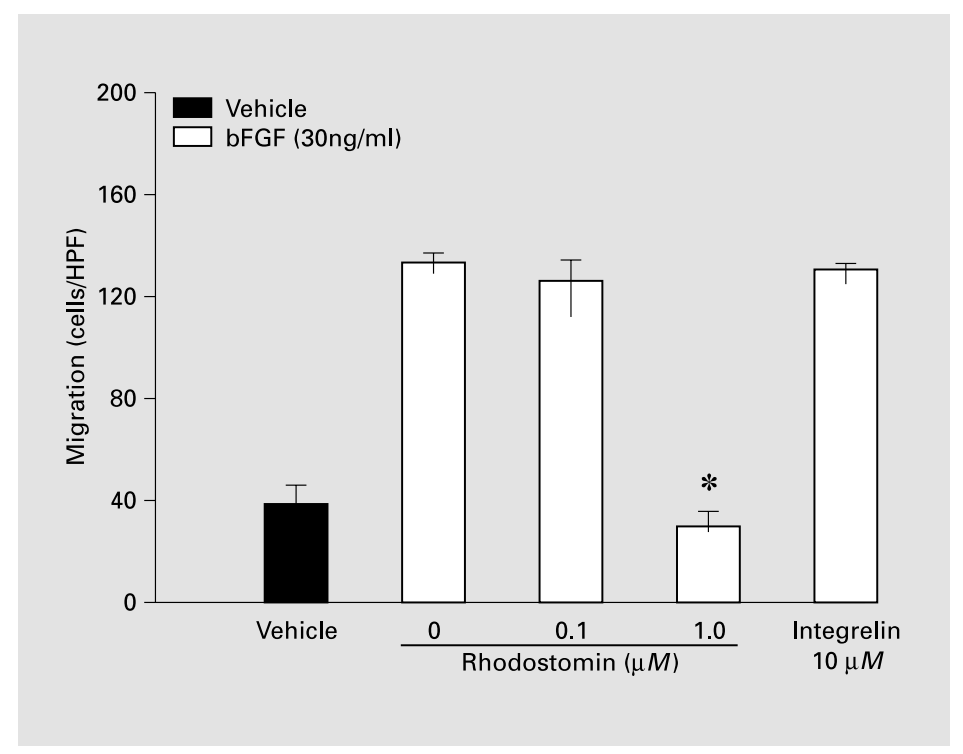

Fig. 2. Rhodostomin inhibited HUVEC migration toward bFGF. HUVECs $\left(5 \times 10^{4} / \mathrm{ml}\right)$ were treated with the indicated concentration of test compounds or PBS (vehicle) for $30 \mathrm{~min}$ and then placed in the upper chamber of Transwell containing a gelatin-coated filter membrane. Chemotaxis was induced by adding bFGF $(30 \mathrm{ng} / \mathrm{ml})$ to the lower chamber for $16 \mathrm{~h}$. After fixation and removing nonmigrated cells, cells that migrated to the underside of the filter membrane were photographed and quantified by phase-contrast light microscope under high power field (HPF, magnification: $\times 100$ ). All experiments were conducted in triplicate and similar results were repeated at least four times. Data are presented as means $\pm \operatorname{SEM}(n=4-5) . * \mathrm{p}<$ 0.01 vs. bFGF alone.
2\% FBS). Rhodostomin (but not integrelin, $10 \mu M$ ) inhibited bFGF-induced HUVEC proliferation as examined by cell number counting (fig. 1a), cell metabolic activity (fig. 1b) and BrdU-labeling index (fig. 1c), in a dose-dependent manner with $\mathrm{IC}_{50}$ values of $0.24,0.36$ and $0.27 \mu M$, respectively. Moreover, at a higher concentration (i.e., $1 \mu M$ ), rhodostomin significantly inhibited HUVEC proliferation, compared with that of resting cells (control in $2 \%$ FBS, $p<0.01$ for fig. $1 \mathrm{a}, \mathrm{b}$; $\mathrm{p}<0.05$ for fig. $1 \mathrm{c})$. However, the viability of B16F10 melanoma tumor cells was not significantly decreased upon incubation with rhodostomin $(5-50 \mu M)$ for 24-72 $\mathrm{h}$, as examined by an MTT assay (fig. 1d). Furthermore, rhodostomin (0.1-0.6 $\mu M$, data not shown), as well as accutin (0.1-0.8 $\mu M$ [21]) dose dependently induced apoptosis when coincubated with HUVECs, as examined by flow cytometric cell cycle analysis. However, rhodostomin did not impair cell vitality, as measured by trypan blue exclusion, if HUVECs were incubated with rhodostomin in suspension ( $>90 \%$ exclusion, data not shown). These results indicate that the antiproliferative activity of rhodostomin is specifically restricted to anchorage-dependent cells (e.g. HUVECs).

\section{Effects of Disintegrin and GPIb Antagonist on HUVEC Migration and Invasion}

Angiogenesis is highly dependent on endothelial cell motility and invasion. Therefore, we examined the effects of rhodostomin on 
Fig. 3. Rhodostomin inhibited bFGF-induced HUVEC invasion through Matrigel. Invasion assay was performed by using Transwell containing a Matrigel-coated filter membrane with or without addition of bFGF $(30 \mathrm{ng} / \mathrm{ml})$ in the lower chamber. HUVECs $\left(5 \times 10^{4} /\right.$ $\mathrm{ml}$ ) were placed in the upper chamber in the presence or absence (vehicle) of test compounds. After a 16-hour incubation, cells that invaded to the underside of the filter membrane were quantified. All experiments were conducted in duplicate and repeated at least four times. Data are presented as means $\pm \operatorname{SEM}(\mathrm{n}=4) .{ }^{*} \mathrm{p}<0.01$ vs. bFGF alone.

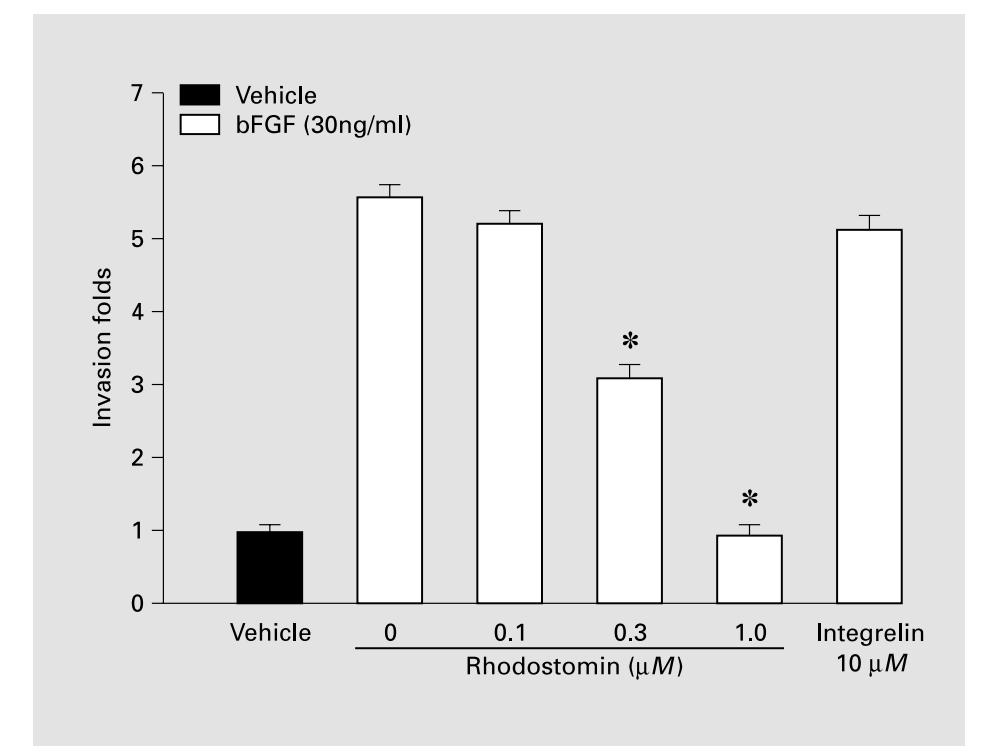

HUVEC migration toward bFGF. Chemotaxic migration was performed by Transwell containing insert filter coated with $0.25 \%$ gelatin. Adhesion of HUVECs toward gelatin was not affected by rhodostomin, even at a high dose of $2 \mu M$ (data not shown). As shown in figure 2, few control cells (without bFGF) were found in lower chamber, whereas a 3.4fold increment of the migrated cells could be detected if bFGF was present as a chemotaxic agent. After a 16-hour incubation, rhodosto$\min (1 \mu M)$ showed a significant inhibition of HUVEC migration (77.6\%), but $0.1 \mu M$ rhodostomin and $10 \mu M$ integrelin exerted little effect (5.1 and 2.1\% inhibition, respectively). For the invasion assay, HUVECs were stimulated by bFGF and penetrated through a uniform layer of Matrigel, which consists of collagen type IV, heparan sulfate proteoglycan, entactin and laminin. bFGF $(30 \mathrm{ng} / \mathrm{ml})$ induced a 5.5 -fold increase in cell invasion through Matrigel, as compared with control (in the absence of bFGF). Moreover, rhodostomin inhibited HUVEC invasion evoked by bFGF in a dose-dependent manner with an $\mathrm{IC}_{50}$ of $0.37 \mu M$ (fig. 3).

To establish the role of GPIb in vWFinduced HUVEC migration, haptotaxis assays were performed that allowed HUVECs to migrate to immobilized $\mathrm{vWF}(10 \mu \mathrm{g} / \mathrm{ml})$, which was coated on the reverse side of the filters. Either rhodostomin $(0.25 \mu M)$ or agkistin $(1 \mu M)$ partially blocked the haptotactic migration response of HUVECs toward immobilized vWF (43 and 37\%, respectively). Moreover, pretreatment of both rhodostomin and agkistin significantly inhibited this migration behavior $(87 \%)$, but $6 \mathrm{~F} 1$ raised against integrin $\alpha_{2} \beta_{1}(20 \mu \mathrm{g} / \mathrm{ml})$ produced less than $10 \%$ inhibition. These results suggest that both endothelial integrin $\alpha_{v} \beta_{3}$ and GPIb receptors, but not $\alpha_{2} \beta_{1}$, contribute to HUVEC migration toward immobilized $\mathrm{vWF}$, and that agkistin is an effective inhibitor on this HUVEC haptotactic migration. 

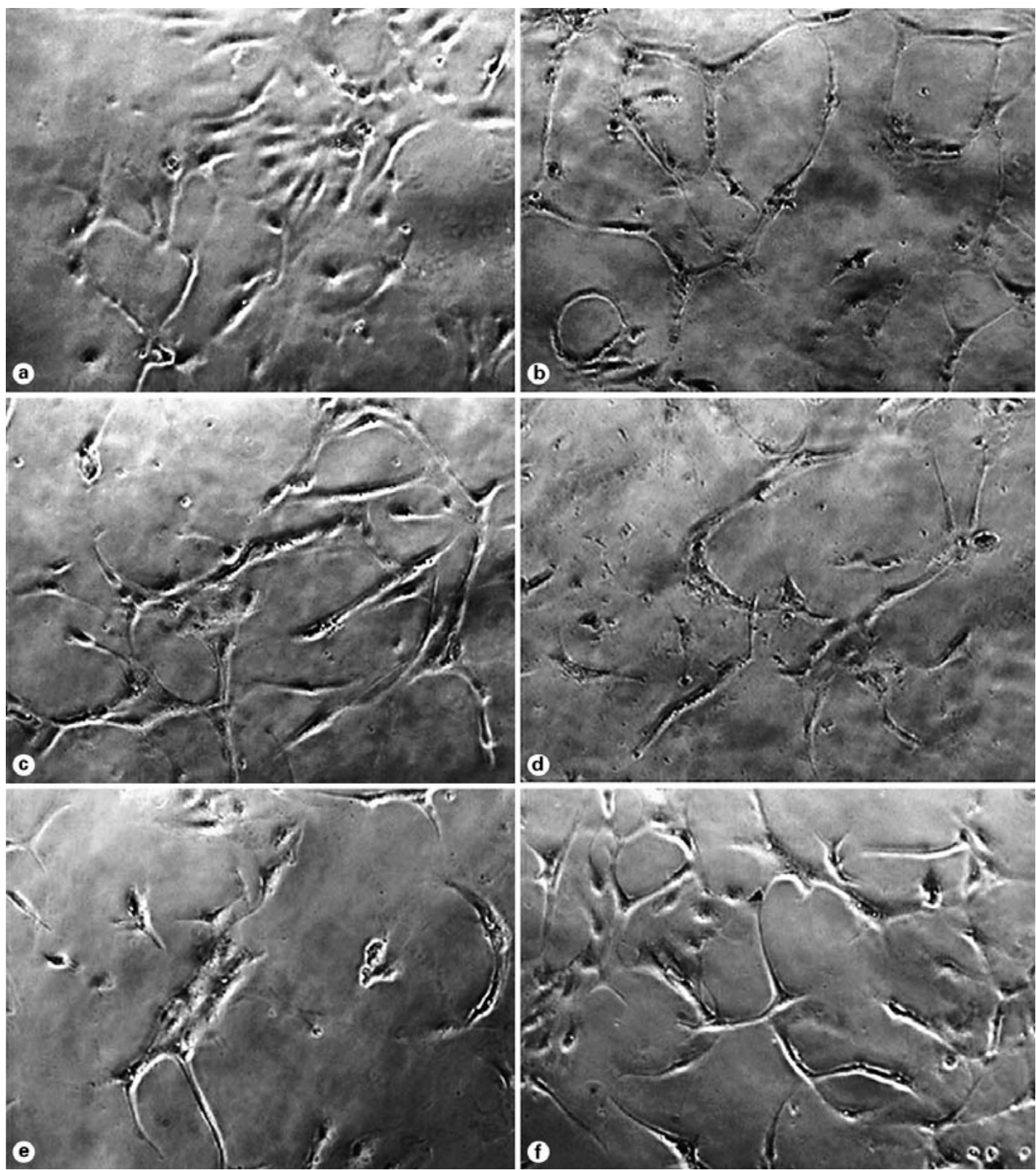

Fig. 4. Rhodostomin inhibited bFGF-induced HUVEC tube formation in diluted Matrigel. HUVECs $\left(2 \times 10^{5} /\right.$ well $)$ were treated with or without the indicated concentration of test compounds and were then plated on diluted Matrigel $(1 \mathrm{mg} / \mathrm{ml})$ in the absence or presence of bFGF for $24 \mathrm{~h}$. After washing and fixation, cells were observed under the microscope at $\times 40$ mag-

nification and photographed. This is a representative experiment of four similar ones. Data are presented as means \pm SEM $(n=4) .{ }^{*} p<0.01$ vs. bFGF alone. a Vehicle. b bFGF $30 \mathrm{ng} / \mathrm{ml}$. c Rhodostomin $0.1 \mu M$. d Rhodostomin $0.3 \mu M$. e Rhodostomin $1 \mu M$. f Integrelin $10 \mu M$. 
Effects of Disintegrin and GPIb Antagonist on Angiogenesis in vitro and in vivo

In vitro angiogenesis assays were carried out by using bFGF-treated HUVECs in a three-dimensional gel consisting of diluted Matrigel $(1 \mathrm{mg} / \mathrm{ml})$. As shown in figure 4, if HUVECs were plated on diluted Matrigel without the addition of exogenous growth factor, they showed only a few spontaneous tube formations and most of them were still in a highly proliferating state with a cobblestone shape (fig. 4a). However, when HUVECs were plated on the diluted Matrigel with addition of bFGF (30 ng/ml), cells displayed high motility, cell-cell communication, aligned and formed an anastomosing capillary-like network within $24 \mathrm{~h}$ (fig. 4b). Rhodostomin significantly decreased the total tube length in each of four randomly chosen fields in a dosedependent manner (fig. $4 \mathrm{c}-\mathrm{e}$ ), in contrast to the minimal effect of integrelin $(10 \mu M$, fig. $4 f$ ). Furthermore, in vivo chick CAM assays were performed under the induction of angiogenesis by both bFGF and VEGF (200 $\mathrm{ng} / \mathrm{embryo}$ ) for $48 \mathrm{~h}$ with or without the addition of rhodostomin (fig. 5). As a control (PBS), formation of new blood vessels under disks on chick embryo CAMs could be observed (fig. 5a). Either bFGF or VEGF induced a pronounced angiogenic response in this model (fig. $5 \mathrm{~b}$ and e, respectively). Rhodostomin, at $2 \mu M$, displayed a significant inhibition on bFGF-induced angiogenesis (fig. $5 \mathrm{c}$ ), as compared to that of bFGF alone, but it slightly affected VEGF-associated angiogenesis (fig. 5f). Similarly, the control peptide integrelin $(2 \mu M)$ exerted little effect on bFGF-induced angiogenic response in the same model (fig. 5d).

Assays of tube formation with agkistin were carried out by using cytokine-primed (TNF- $\alpha$ plus IFN- $\gamma$, for $48 \mathrm{~h}$ ) or naive $(2 \%$ FBS) HUVECs in a thick gel consisting of diluted Matrigel $(1 \mathrm{mg} / \mathrm{ml})$. If HUVECs were grown on diluted Matrigel without the addition of exogenous vWF, they showed little tube formation. On the other hand, when cytokine-primed HUVECs were plated on diluted Matrigel with the addition of vWF $(10 \mu \mathrm{g} / \mathrm{ml})$, they aligned with one another and formed an anatomotic capillary-like network within $24 \mathrm{~h}$. Agkistin $(1 \mu M)$ significantly inhibited this tube formation of cytokineprimed HUVECs on diluted Matrigel in the presence of exogenous vWF (30 ng/ml), but not in the absence of vWF. Moreover, neither agkistin $(5 \mu M)$ nor AP1 $(40 \mu \mathrm{g} / \mathrm{ml})$, an mAb raised against GPIb, affected the spontaneous tube formation of HUVECs induced by a higher concentration of Matrigel $(4 \mathrm{mg} / \mathrm{ml})$, even in the presence of exogenous vWF.

\section{Elucidation of Targeted Receptors of Rhodostomin on Growth Factor-Activated Endothelial Cells}

To identify which integrins expressed on HUVEC interact with rhodostomin, we first examined whether rhodostomin displaces the binding of anti-integrin $\mathrm{mAb}$ toward HUVEC by flow cytometry. As shown in figure 6, the expression of integrin $\alpha_{v} \beta_{3}$ or $\alpha_{v} \beta_{5}$ on HUVECs in naive cells was probed by $7 \mathrm{E} 3$ or P1F6, respectively, and presented as the mean fluorescence intensity. Exposure to either bFGF or VEGF did not significantly affect the expression of $\alpha_{v} \beta_{3}$, but a 2 -fold increment of $\alpha_{\mathrm{v}} \beta_{5}$ expression was detected in VEGF-primed cells. Moreover, a conformational change of $\alpha_{v} \beta_{3}$ following bFGF or VEGF exposure was observed, as probed by an anti-LIBS1 $\mathrm{mAb}$ raised against ligandinduced binding sites of $\beta_{3}$ integrins [22]. Rhodostomin inhibited 7E3 binding toward both naive and bFGF-primed HUVECs in a dose-dependent manner with $\mathrm{IC}_{50}$ values of 2.95 and $1.88 \mu M$, respectively, but had little effects on P1F6-binding reaction under these conditions. 

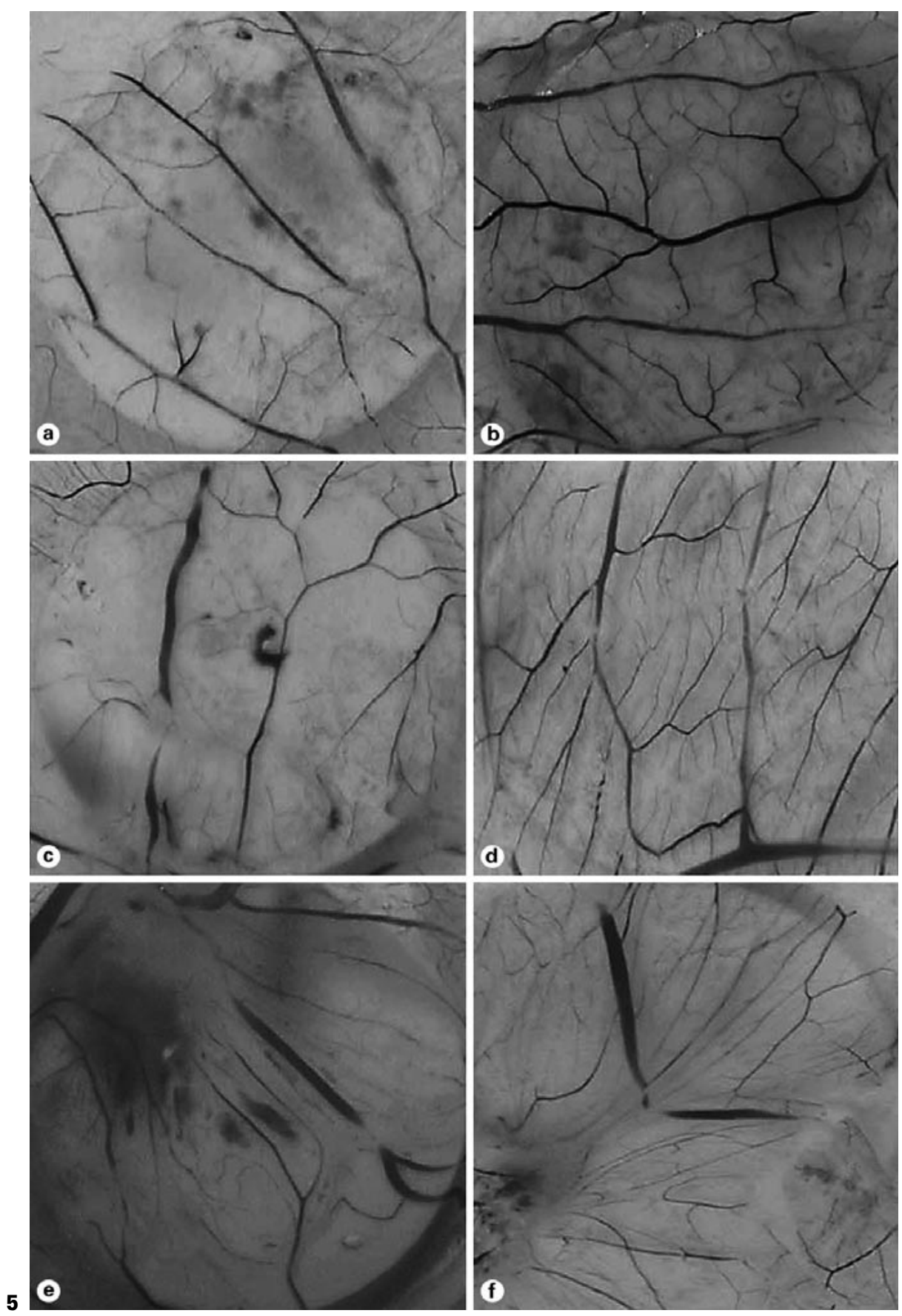
Fig. 6. Effect of growth factors on HUVEC integrin expression and their binding affinity. HUVECs exposed to the standard medium (naive), bFGF or VEGF (both in $30 \mathrm{ng} / \mathrm{ml}$, for $48 \mathrm{~h}$ ) were incubated with primary probe 7E3, P1F6 (both in $20 \mu \mathrm{g} / \mathrm{ml}$ ) or anti-LIBS1 $\mathrm{mAb}(0.17 \mu M)$ and analyzed by flow cytometry. Nonspecific binding was performed by incubating HUVECs with nonimmune IgG (control, 1:50 dilution). Results are represented as mean fluorescence intensity $\pm \operatorname{SEM}(\mathrm{n}=4) .{ }^{*} \mathrm{p}<$ $0.01,{ }^{* *} \mathrm{p}<0.05$ vs. naive.

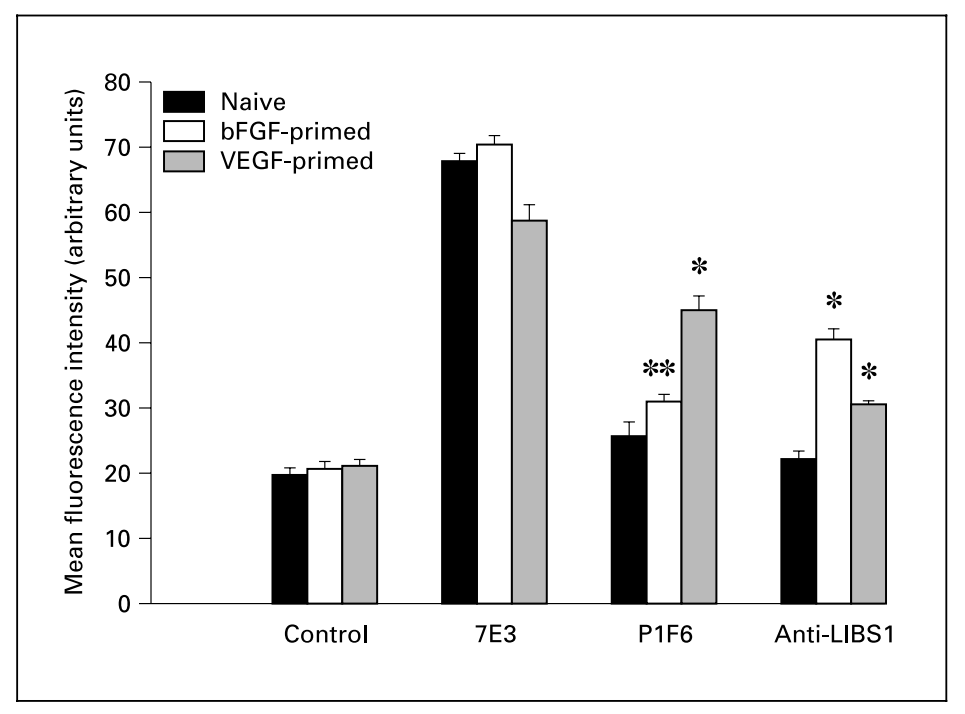

\section{Effect of Rhodostomin on bFGF- and}

Tumor-Associated Angiogenesis in

\section{Matrigel Plug Assays}

Matrigel serves as a vehicle for the slow release of angiogenic factor since it exists as a liquid at $4{ }^{\circ} \mathrm{C}$, but forms a gel in vivo. The formed gel, after subcutaneous injection of Matrigel alone, was readily distinguished from surrounding tissue and produced little local reaction or angiogenic response [23]. In the presence of bFGF $(500 \mathrm{ng} /$ mouse, fig. 7a) or B16F10 murine melanoma cells $\left(3 \times 10^{6}\right)$ mouse, fig. 7c), Matrigel plug induced intense

Fig. 5. Rhodostomin inhibited bFGF-induced angiogenesis in chick CAM assays. Filter disks soaked in buffer (a, vehicle), bFGF or VEGF alone (b, e, respectively, both in $200 \mathrm{ng} / \mathrm{embryo}$ ) or growth factor plus the indicated compounds in a total volume of $20 \mu \mathrm{l}$ were applied on 10-day-old CAMs. After a 48-hour incubation, each CAM under disk was resected, fixed and photographed. This is a representative experiment of three similar ones. a PBS. b bFGF only. $\mathbf{c}$ bFGF + rhodostomin $2 \mu M$. d bFGF + integrelin $2 \mu M$. e VEGF only. f VEGF + rhodostomin $2 \mu M$. vascularization in vivo 14 days after implantation, as examined by immunohistological staining for $\mathrm{vWF}$, an endothelial-specific antigen. Rhodostomin $(50 \mu M)$ significantly inhibited both bFGF (fig. 7b) and B16F10 cellinduced angiogenesis (fig. 7d) in the murine experimental model.

\section{Effect of Rhodostomin on Subcutaneous B16F10 Tumor Growth and Survival Rate of Tumor-Bearing Mice}

To examine the antitumor activity of disintegrin, we examined the effect of rhodostomin on the B16F10 tumor model in C57BL/6 mice. As shown in figure 8 , the $\mathrm{B} 16 \mathrm{~F} 10$ tumor-bearing mice exhibited aggressive tumor growth kinetics, as observed in the control group (PBS treatment). After coadministration of B16F10 cells with rhodostomin (5 and $50 \mu M$ ), both tumor growth rate and tumor volumes were significantly reduced, compared with those coinjected with B16F10 cells with PBS or integrelin $(50 \mu M)$. It was necessary to sacrifice the animals receiving coinjection because the tumors were large (i.e., 


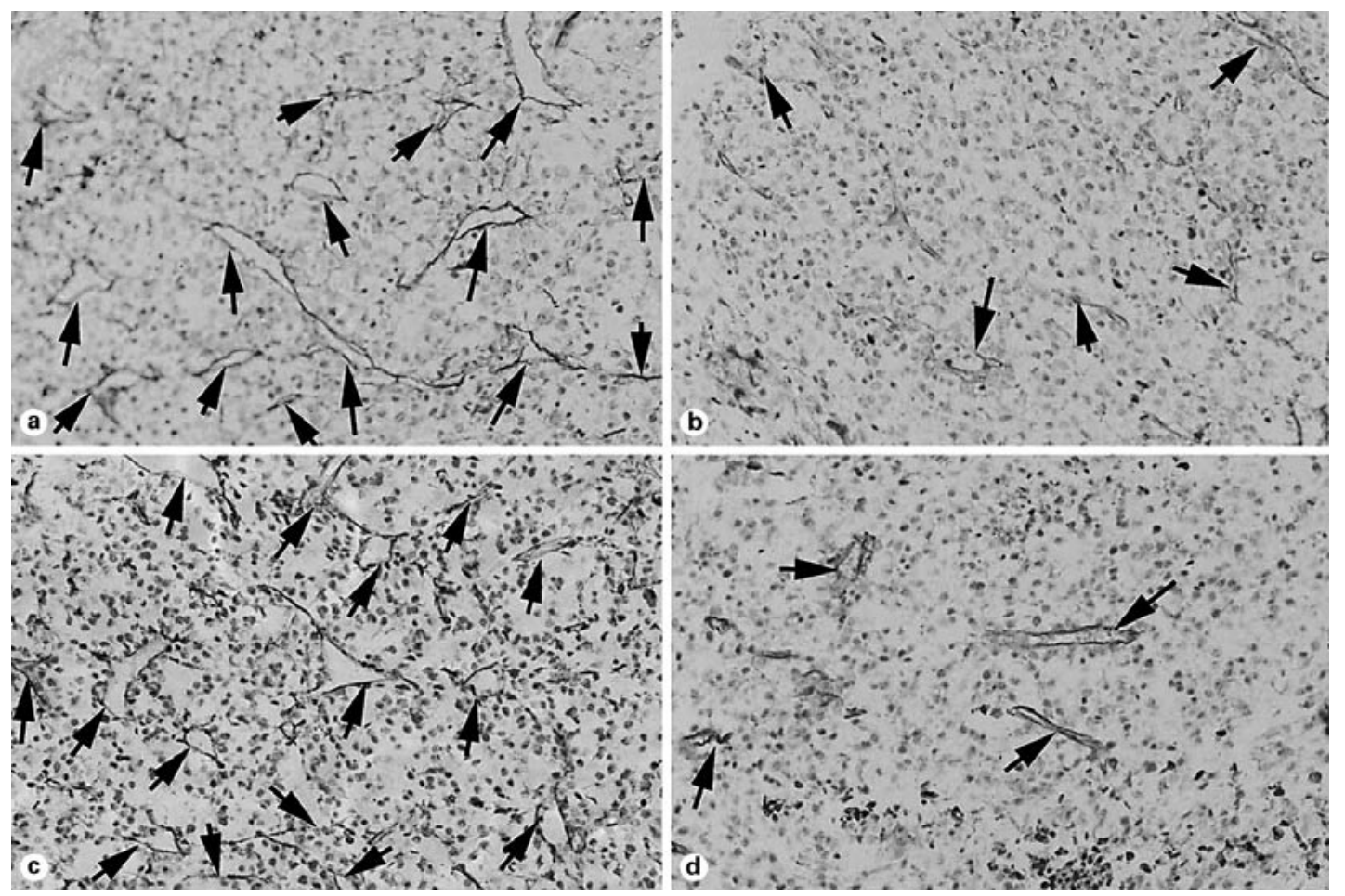

Fig. 7. Effect of rhodostomin on bFGF or B16F10 tumor melanoma cell-induced angiogenesis in Matrigel plug murine model. An aliquot of Matrigel $(0.5 \mathrm{ml})$ supplemented with bFGF $(500 \mathrm{ng}, \mathbf{a}, \mathbf{b})$ or B16F10 melanoma cells $\left(3 \times 10^{6}, \mathbf{c}, \mathbf{d}\right)$ in the absence $(\mathbf{a}, \mathbf{c})$ or presence of rhodostomin $(50 \mu M, \mathbf{b}, \mathbf{d})$ was subcutaneously injected into the dorsal region of B57CL/6 mice. Analyses of the vasculature of respective Matrigel from the mice 14 days after the implantation were performed by immunohistochemical staining for vWFantigen that were indicated by arrowheads in the figure. Magnification: $\times 180$.

$4,806.56 \pm 614.58$ and $4,530.7 \pm 719.56$ $\mathrm{mm}^{3}$, respectively). In contrast, cells coinjected with rhodostomin $(5$ and $50 \mu M)$ grew significantly smaller tumors in mice (i.e., $2,908.42 \pm 445.39$ and $485.29 \pm 134.83$ $\mathrm{mm}^{3}$, respectively), compared with those arising from the control group ( $\mathrm{p}<0.05$ and $\mathrm{p}<$ 0.01 , respectively). Moreover, the survival rates of $\mathrm{B} 16 \mathrm{~F} 10$ tumor-bearing animals receiving rhodostomin $(5$ and $50 \mu M)$ also increased, compared with those mice receiving vehicle (PBS) or integrelin $(50 \mu M$, data not shown). Thus, rhodostomin appears to be ef- fective in the treatment of mice suffering from solid tumor progression of B16F10 melanoma, not only by reducing the tumor growth rate but also by reducing the consequent mortality.

\section{Discussion}

The role of integrin $\alpha_{v} \beta_{3}$ in mediating crucial angiogenic processes has led to the conclusion that this integrin facilitates the survival of stimulated endothelial cells [24]. We 


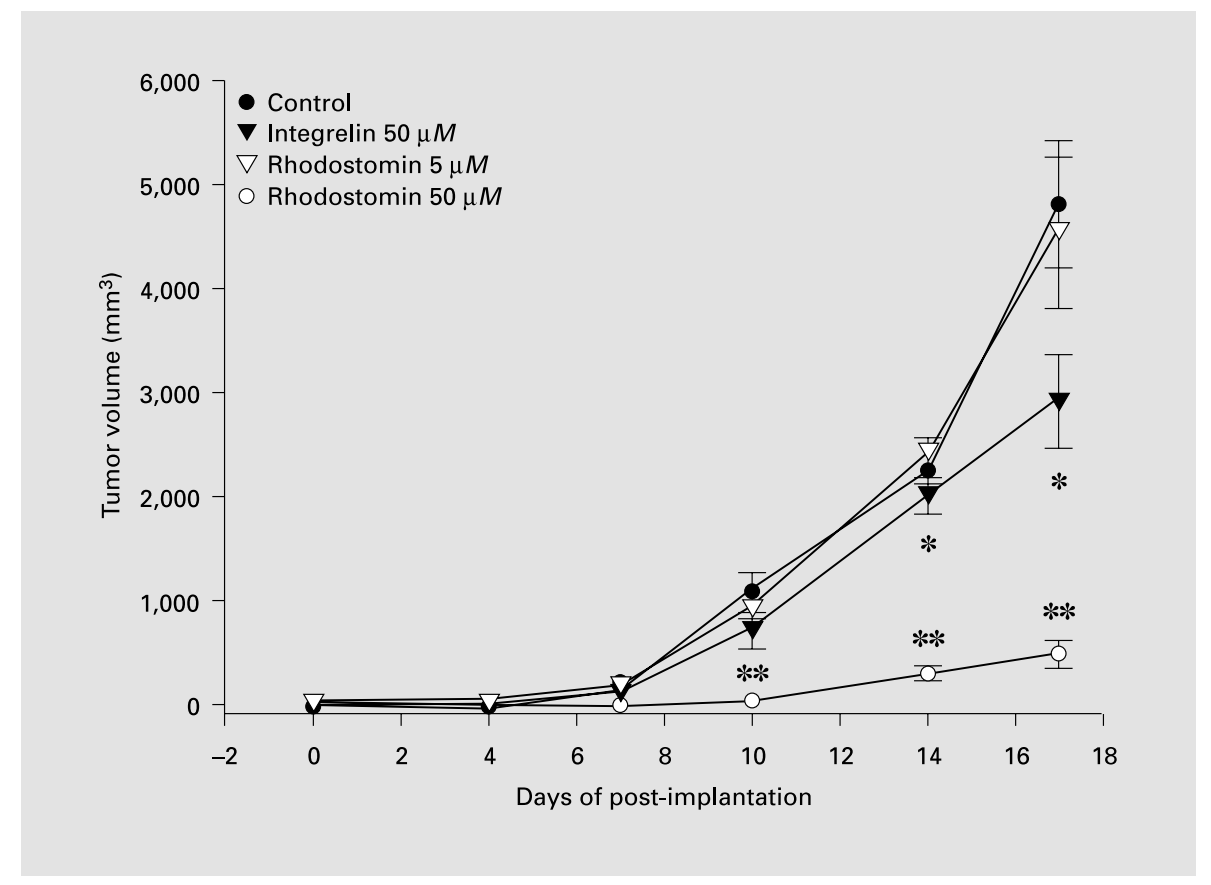

Fig. 8. Effect of rhodostomin on subcutaneous B16F10 tumor growth. B16F10 melanoma cells $\left(3 \times 10^{6} /\right.$ mouse) were subcutaneously injected in the dorsal region of B57CL/6 mice, in the absence (control: $\bigcirc$ ) or presence of rhodostomin: $5(\nabla)$ or $50 \mu M(\bigcirc)$ or integrelin $(50 \mu M$, $\boldsymbol{\nabla})$ in a final volume of $0.3 \mathrm{ml}$. Tumor volumes were monitored by periodic caliper measurements and presented as means \pm SEM, $\mathrm{n}=9-11 .{ }^{*} \mathrm{p}<0.05 ;{ }^{* *} \mathrm{p}<0.01$, compared with control group on the same day.

showed here that rhodostomin inhibited bFGF-induced human endothelial cell proliferation at submicromolar concentrations, as examined by using various methods, including determination of total cell number, metabolic activity and BrdU labeling index. However, rhodostomin did not decrease B16F10 melanoma cell viability, even up to $50 \mu M$, as determined by an MTT assay. Several lines of evidence indicate that endothelial cell apoptosis plays a critical regulatory role in angiogenesis [25]. Moreover, primary cultured endothelial cells are anchorage dependent. The selective antiproliferating effect of rhodostomin on primary cultured endothelial cells is related to the induction of apoptosis, as evidenced by flow cytometric cell cycle analysis, but it did not cause any cytotoxic effect, as revealed by trypan blue exclusion. This is consistent with the previous observations that RGD peptides and disintegrin (i.e., accutin) induce an apoptotic effect toward HUVECs $[26,21]$, but not toward melanoma tumor cells $[27,28]$.

A close interaction exists among cell motility, integrin receptors, and soluble angiogenic factors during each step of the angiogenic processes. Upon angiogenesis, integrin $\alpha_{v} \beta_{3}$ and the receptor for bFGF cooperate to promote signaling events, thereby facilitating the in- 
duction and/or maintenance of the angiogenic phenotype [29]. In the present study, we demonstrated that rhodostomin dose dependently exhibited inhibitory effects on HUVEC migration and invasion evoked by bFGF. Cytokines have been reported to trigger signaling pathways leading to the modulation of expression and/or ligand affinity of integrin $\alpha_{\mathrm{v}} \beta_{3}$ on endothelial cells $[5,30]$. Recent studies also showed that integrin $\alpha_{v} \beta_{3}$ could exist in different activation states [31]. Unlike the previous studies, which demonstrate that bFGF increases the expression of integrin $\alpha_{v} \beta_{3}$ in cultured microvascular endothelial cells [32, 33], our data in this work indicate that exposure to bFGF promotes the ligand affinity of $\alpha_{\mathrm{v}} \beta_{3}$ for anti-LIBS1 $\mathrm{mAb}$ without increasing its expression on HUVECs, as examined by flow cytometry. The difference in $\alpha_{\mathrm{v}} \beta_{3}$ expression may be dependent on the tissue of origin, as well as the maturity of endothelial cells.

Several models have been used to study the role of cell adhesion molecules in angiogenesis, including the Matrigel tube formation model, chick CAM assay and the murine Matrigel plug model [34]. Rhodostomin is an effective inhibitor of bFGF-associated angiogenesis in vitro and in vivo, as examined by multiple models described above. However, rhodostomin did not interfere with VEGFassociated formation of blood vessels in CAM model. Regarding the binding site of rhodostomin to HUVEC, rhodostomin dose dependently inhibited 7E3 (i.e., an anti- $\alpha_{\mathrm{IIb}} \beta_{3}$ and $\alpha_{\mathrm{v}} \beta_{3} \mathrm{mAb}$ ), but not P1F6 (i.e., an anti- $\alpha_{\mathrm{v}} \beta_{5}$ $\mathrm{mAb}$ ) binding to both naive and bFGFprimed HUVECs. Therefore, the action of rhodostomin in suppressing bFGF-elicited angiogenesis is due to the specific blockade of $\alpha_{v} \beta_{3}$ ligation rather than $\alpha_{v} \beta_{5}$ ligation of the activated endothelial cells. In addition to the modulation of $\alpha_{v} \beta_{3}$ and $\alpha_{v} \beta_{5}$ integrins by bFGF and VEGF, respectively, as examined by flow cytometry, these results are consistent with the previous report that two cytokinedependent pathways of angiogenesis have been proposed, based on their dependence on distinct vascular cell $\alpha_{v}$ integrins [7]. Furthermore, rhodostomin markedly inhibited tumor angiogenesis in murine Matrigel plug models elicited by B16F10 melanoma tumor cells. The antitumor angiogenesis effects of rhodostomin may play a critical role in inhibiting the growth rate of solid B16F10 melanoma tumor and in prolonging survival kinetics of tumor-bearing animals. Similar results were also reported with salmosin and contortrostatin, two snake venom-derived disintegrins $[35,36]$.

In our serial studies, we showed that both snake venom-derived disintegrins and $\mathrm{GPIb}$ antagonist are effective inhibitors of angiogenesis [21, 37, 38]. Disintegrins inhibited angiogenesis by acting as an integrin $\alpha_{\mathrm{v}} \beta_{3}$ antagonist and by inducing apoptosis [21], while GPIb antagonist disrupted interaction of vWF-endothelial GPIb and inhibited angiogenesis [37], although both of them suppress angiogenesis by blocking endothelial adhesive receptors ligation with ECMs. However, there are several differences between these two families of antiangiogenic snake proteins. First, disintegrins exerted a potent inhibition on growth factor-induced HUVEC proliferation [38], whereas GPIb antagonist did not. Second, disintegrins significantly inhibited Matrigel-induced tube formation of HUVECs in the absence of exogenous substances [21], but GPIb antagonist showed little effect. Third, disintegrins inhibited angiogenesis in vivo without affecting preexisting blood vessel in a chick CAM model [21]; however, GPIb antagonist significantly disrupted pre-existing blood vessels, as evidenced by the disappearance of large vessels in the same model [37]. Thus, the actions of antiangiogenic activity of GPIb antagonist are quite different from those of disintegrins. These observa- 
tions also suggest that GPIb and integrin $\alpha_{\mathrm{v}} \beta_{3}$ may play different roles in angiogenesis. A combination of rhodostomin and agkistin exhibited an additive or synergistic effect by suppressing HUVEC migration, raising a hypothesis that the blockade of endothelial GPIb and $\alpha_{v} \beta_{3}$ may have additive or synergistic effects on angiogenesis. However, this needs to be confirmed.

The results of this study demonstrate that exposure of HUVECs to TNF- $\alpha$ plus IFN- $\gamma$ upregulated both the expression of functional GPIb protein and of mRNA in these cells, thereby increasing a GPIb-dependent endothelial cell adhesion to immobilized agkistin. The suppression mechanisms of agkistin in cytokine-induced multiple angiogenic process mainly result from its inhibitory effect on endothelial cell migration and tube formation, but not on proliferation. The elucidation of the antiangiogenic mechanism of agkistin based on structure-activity relationship studies may be helpful in designing a new therapeutic strategy in angiogenesis-related diseases.

\section{Acknowledgments}

We appreciate very much the generous supply of mAbs, 7E3 from Dr. B.S. Coller (Mount Sinai Hospital, New York, N.Y., USA), anti-LIBS1 and AP1 from Dr. M.H. Ginsberg and Dr. R. Montgomery, respectively (Research Institute of Scripps, La Jolla, Calif., USA). This work was supported by NSC-90-2320B002-084.

\section{References}

1 Folkman J: Seminars in Medicine of the Beth Israel Hospital, Boston. Clinical applications of research on angiogenesis. N Engl J Med 1995; 333:1757-1763.

2 Folkman J, Shing Y: Angiogenesis. J Biol Chem 1992;267:10931-10934.

3 Sastry SK, Horwitz AF: Adhesiongrowth factor interactions during differentiation: An integrated biological response. Dev Biol 1996;180: 455-467.

4 Hynes RO: Integrins: Versatility, modulation, and signaling in cell adhesion. Cell 1992;69:11-25.

5 Byzova TV, Rabbani R, D’Souza SE, Plow EF: Role of integrin $\alpha_{\mathrm{v}} \beta_{3}$ in vascular biology. Thromb Haemost 1998;80:726-734.

6 Brooks PC, Clark RAF, Cheresh DA: Requirement of vascular integrin $\alpha_{\mathrm{v}} \beta_{3}$ for angiogenesis. Science 1994;264:569-571.

7 Friedlander M, Brooks PC, Shaffer RW, Kincaid CM, Varner JA, Cheresh DA: Definition of two angiogenic pathways by distinct $\alpha_{\mathrm{v}}$ integrins. Science 1995;270:1500-1502.
8 Sadler JE: von Willebrand factor. J Biol Chem 1991;266:22777-22780.

9 Wu G, Essex DW, Meloni FJ, et al: Human endothelial cells in culture and in vivo express on their surface all four components of the glycoprotein Ib/IX/V complex. Blood 1997; 90:2660-2669.

10 Beacham DA, Tran LP, Shapiro SS: Cytokine treatment of endothelial cells increases glycoprotein Ib $\alpha$-dependent adhesion to von Willebrand factor. Blood 1997;89:4071-4077.

11 Konkle BA, Shapiro SS, Asch AS, Nachman RL: Cytokine-enhanced expression of glycoprotein Iba in human endothelium. J Biol Chem 1990;265:19833-19838.

12 Rajagopalan V, Essex DW, Shapiro SS, Konkle BA: Tumor necrosis factor- $\alpha$ modulation of glycoprotein Ibo expression in human endothelial and erythroleukemia cells. Blood 1992;80:153-161.

13 Wick TM, Moake JL, Udden MM, McIntire LV: Unusually large von Willebrand factor multimers preferentially promote young sickle and nonsickle erythrocyte adhesion to endothelial cells. Am J Hematol 1993;42:284-292.
14 Bombeli T, Schwatz BR, Harian JM: Adhesion of activated platelets to endothelial cells: Evidence for a GPIIbIIIa-dependent bridging mechanism and novel roles for endothelial intercellular adhesion molecule I (ICAM-1), $\alpha_{\mathrm{v}} \beta_{3}$ integrin and GPIba. J Exp Med 1998;187:329339.

15 Lian J, Guoping C, Shapiro SS, Tran LP, Beacham DA: Glycoprotein $\mathrm{Ib}_{\alpha}$ can mediate endothelial cell migration on von Willebrand factor-containing substrata. Exp Cell Res 1999;252:114-122.

16 Gould RJ, Polokoff MA, Friedman PA, Huang TF, Holt JC, Cook JJ, Niewiarowski S: Disintegrins: A family of integrin inhibitory proteins from viper venoms. Proc Soc Exp Biol Med 1990;195:168-171.

17 Fujimura Y, Kawasaki T, Titani K: Snake venom proteins modulating the interaction between von Willebrand factor and platelet glycoprotein Ib. Thromb Haemost 1996;76: 633-639. 
18 Tan L, Kowalska MA, Romo GM, Lopez JA, Darzynkiewicz Z, Niewiarowski $S$ : Identification and characterization of endothelial glycoprotein Ib using viper venom proteins modulating cell adhesion. Blood 1999;93:2605-2616.

19 Chen YL, Tsai IH: Functional and Sequence characterization of agkicetin, a new glycoprotein Ib antagonist isolated from Agkistrodon acutus venom. Biochem Biophys Res Commun 1995;210:472-477.

20 Yeh $\mathrm{CH}$, Chang MC, Peng HC, Huang TF: Pharmacological characterization and antithrombotic effect of agkistin, a platelet glycoprotein $\mathrm{Ib}$ antagonist. Br J Pharmacol 2001; 132:843-850.

21 Yeh CH, Peng HC, Huang TF: Accutin, a new disintegrin, inhibits angiogenesis in vitro and in vivo by acting as integrin $\alpha_{\mathrm{v}} \beta_{3}$ antagonist and inducing apoptosis. Blood 1998; 92:3268-3276.

22 Frelinger AL 3rd, Cohen I, Plow EF, Smith MA, Robert J, Lam SCT, Ginsberg MH: Selective inhibition of integrin function by antibodies specific for ligand-occupied receptor conformers. J Biol Chem 1990;265: 6346-6352.

23 Passaniti A, Taylor RM, Pili R, Gou Y, Long PV, Haney JA, Pauly RR, Grant DS, Martin GR: A simple, quantitative method for assessing angiogenesis and antiangiogenic agents using reconstituted basement membrane, heparin, and fibroblast growth factor. Lab Invest 1992;67: 519-529.
24 Eliceiri BP, Cheresh DA: The role of $\alpha_{\mathrm{v}}$ integrins during angiogenesis: Insights into potential mechanisms of action and clinical development. J Clin Invest 1999;103:1227-1230.

25 Dimmeler S, Zeiher AM: Endothelial cell apoptosis in angiogenesis and vessel regression. Circ Res 2000;87:434-439.

26 Brooks PC, Montgomery AMP, Rosenfeld M, Reisfeld RA, Hu T, Klier $\mathrm{G}$, Cheresh DA: Integrin $\alpha_{\mathrm{v}} \beta_{3}$ antagonists promote tumor regression by inducing apoptosis of angiogenic blood vessels. Cell 1994;79:11571164.

27 Mitjans F, Meyer T, Fittschen C, Goodman S, Jonczyk A, Marshall JF, Reyes G, Piulats J: In vivo therapy of malignant melanoma by means of antagonists of $\alpha_{\mathrm{v}}$ integrins. Int J Cancer 2000;87:716-723.

28 Allman R, Cowburn P, Mason M: In vitro and in vivo effects of a cyclic peptide with affinity for the $\alpha_{v} \beta_{3}$ integrin in human melanoma cells. Eur J Cancer 2000;36:410-422.

29 Plopper GE, McNames HP, Dike LE, Bojanowski K, Ingber DE: Convergence of integrin and growth factor receptor signaling pathways within the focal adhesion complex. Mol Biol Cell 1995;6:1349-1365.

30 Yeh CH, Peng HC, Huang TF: Cytokines modulate integrin $\alpha_{v} \beta_{3}$-mediated human endothelial cell adhesion and calcium signaling. Exp Cell Res 1999;251:57-66.

31 Byzova TV, Plow EF: Activation of $\alpha_{\mathrm{v}} \beta_{3}$ on vascular cells controls recognition of prothrombin. J Cell Biol 1998;143:2081-2092.
32 Enenstein J, Waleh NS, Kramer RH: Basic FGF and TGF-beta differentially modulate integrin expression of human microvascular endothelial cells. Exp Cell Res 1992;203: 499-503.

33 Klein S, Giancotti FG, Presta M, Albelda SM, Buck CA, Rifkin DB: Basic fibroblast growth factor modulates integrin expression in microvascular endothelial cells. Mol Biol Cell 1993;4:973-982.

34 Stromblad S, Cheresh DA: Cell adhesion and angiogenesis. Trends Cell Biol 1996;6:462-468.

35 Kang IC, Lee YD, Kim D: A novel disintegrin salmosin inhibits tumor angiogenesis. Cancer Res 1999;59: 3754-3760.

36 Zhou Q, Nakada MT, Arnold C, Shieh KY, Markland FS: Contortrostatin, a dimeric disintegrin from Agkistrodon contortrix contortrix, inhibits angiogenesis. Angiogenesis 1999;3:259-269.

37 Yeh $\mathrm{CH}$, Wang WC, Hsieh TT, Huang TF: Agkistin, a snake venom-derived glycoprotein Ib antagonist, disrupts von Willebrand factorendothelial cell interaction and inhibits angiogenesis. J Biol Chem 2000;275:18615-18618.

38 Yeh CH, Peng HC, Yang RS, Huang TF: Rhodostomin, a snake venom disintegrin, inhibits angiogenesis elicited by basic fibroblast growth factor and suppresses tumor growth by a selective $\alpha_{\mathrm{v}} \beta_{3}$ blockade of endothelial cells. Mol Pharmacol 2001; 59:1333-1342. 